\title{
Contributor to Volume 52, Number 3
}

William Bright is Professor Adjoint of Linguistics, Dept. of Colorado, Boulder, CO 80302, USA. His interests include anthropological linguistics, Native American languages, and toponomastics. His latest book is Native American Placenames of the United States (Norman: University of Oklahoma Press, 2004). 